\author{
B. Charbonnel $\cdot$ M. Roden $\cdot$ R. Urquhart $\cdot$ S. Mariz $\cdot$ \\ D. Johns $\cdot$ M. Mihm $\cdot$ M. Widel $\cdot$ M. Tan
}

\title{
Pioglitazone elicits long-term improvements in insulin sensitivity in patients with type 2 diabetes: comparisons with gliclazide-based regimens
}

Received: 1 April 2004 / Accepted: 12 November 2004 / Published online: 1 March 2005

(C) Springer-Verlag 2005

\begin{abstract}
Aims/hypothesis: Recent studies have demonstrated that pioglitazone (PIO) has beneficial effects on insulin sensitivity compared with placebo in patients with type 2 diabetes. The effects of PIO and gliclazide (GLIC)based therapy on insulin sensitivity have not previously been directly compared. This analysis aimed to compare the effects of 52 weeks of treatment with PIO (30-45 mg/day) and GLIC (80-320 mg/day), both titrated to maximum tolerable doses, as monotherapy or in combination with metformin (MET), on insulin sensitivity and lipid parameters known to be related to insulin sensitivity in patients with type 2 diabetes. Methods: We performed an analysis of 1,880 patients with inadequately controlled type 2 diabetes $\left(\mathrm{HbA}_{1} \mathrm{c} 7.5-11.0 \%\right)$ who were participants in two parallelgroup, double-blind, double-dummy, randomised, multicentre, clinical trials. Measures of insulin sensitivity and lipids were assessed. Results: The PIO- and GLIC-based regimens produced similar levels of glycaemic control $\left(\mathrm{HbA}_{1} \mathrm{c}\right)$. In both trials, insulin sensitivity as assessed using the homeostasis model assessment was improved in patients receiving PIO, but decreased in those receiving GLIC (mean change, baseline to endpoint: PIO 15.5, GLIC-15.6; $p<0.001$ and PIO+MET 18.9, GLIC+MET $-5.3 ; p<0.001)$. Improvements in the atherogenic index of plasma (mean change: PIO -0.17 , GLIC $-0.08 ; p<0.001$ and PIO+MET
\end{abstract}

B. Charbonnel

Endocrinology Clinic, Hotel Dieu Hospital,

Nantes, France

M. Roden

Department of Internal Medicine, Hanusch Hospital,

Vienna, Austria

R. Urquhart $\cdot$ S. Mariz

Takeda Europe R\&D Centre,

London, UK

D. Johns $\cdot$ M. Mihm $\cdot$ M. Widel $\cdot$ M. Tan $(\square)$

Eli Lilly and Company, Lilly Corporate Centre,

Indianapolis, IN, 46285, USA

e-mail: tan_meng@lilly.com

Tel.: +1-317-4330251

Fax: $+1-317-2775458$
-0.17 , GLIC+MET $-0.02 ; p<0.001$ ), triglycerides (mean change, $\mathrm{mmol} / \mathrm{l}$ : PIO+MET -0.62 , GLIC+MET $-0.22 ; p<$ 0.001 ) and NEFA (mean change, $\mathrm{mmol} / \mathrm{l}$ : PIO+MET -0.12 , GLIC+MET- $0.05 ; p<0.001)$ were greater in PIO-treated patients than in patients receiving GLIC. Conclusions/ interpretation: The PIO-based regimens resulted in improved insulin sensitivity and more favourable insulin sensitivity-related lipid profiles compared with the GLIC-based regimens. These benefits may be important in the management of cardiovascular risk in patients with type 2 diabetes.

Keywords Gliclazide - Homeostasis model assessment . Insulin resistance Pioglitazone Type 2 diabetes

Abbreviations AIP: Atherogenic index of plasma . GLIC: Gliclazide · HOMA: Homeostasis model assessment - MET: Metformin - PIO: Pioglitazone · QUICKI: Quantitative insulin sensitivity check index

\section{Introduction}

Sulphonylureas, such as gliclazide (GLIC), are oral antihyperglycaemic medications that are used in patients with type 2 diabetes when dietary and exercise modifications fail to achieve glycaemic targets. Sulphonylureas improve glycaemic control by directly stimulating insulin secretion from pancreatic beta cells [1]. Patients receiving sulphonylureas often achieve an initial improvement in glycaemic control; however, this drug class has been associated with secondary failure and does not directly address insulin resistance as a core defect of type 2 diabetes [2].

Thiazolidinediones, such as pioglitazone (PIO), improve glycaemic control by increasing insulin sensitivity in the liver and peripheral tissues [3]. PIO is an agonist for the peroxisome proliferator-activated receptor- $\gamma$, which regulates multiple genes controlling carbohydrate and lipid metabolism [4]. In a recent 52-week head-to-head study, PIO monotherapy produced a reduction in $\mathrm{HbA}_{1} \mathrm{c}$ similar to that observed with GLIC (1.4-1.5\%), while producing significantly greater reductions in fasting plasma glucose, 
triglycerides, and HDL cholesterol [5]. In a companion study, the addition of either agent to pre-existing metformin (MET) therapy produced similar decreases in $\mathrm{HbA}_{1} \mathrm{c}(1.2-$ $1.4 \%$ ) and fasting plasma glucose [6]. PIO is now approved in Europe for glycaemic control in patients with type 2 diabetes, both as monotherapy (in metformin-intolerant patients) and as a component of combination therapy with sulphonylureas or MET.

Insulin resistance and diabetic dyslipidaemia are associated with increased cardiovascular risk [7-11]. Despite similar efficacy with respect to glycaemic control $\left(\mathrm{HbA}_{1} \mathrm{c}\right)$, PIO and GLIC may affect insulin resistance and diabetic dyslipidaemia differently because of their different mechanisms of action. The aim of these analyses was to compare the effects of PIO and GLIC on insulin sensitivity, beta cell activity and selected lipid parameters that are known to modulate insulin sensitivity in adults with type 2 diabetes, so as to extend the findings previously reported by the two clinical trials described above $[5,6]$.

\section{Materials and methods}

Patients and study design The current report describes analyses of the results from two 52-week, randomised, double-blind, double-dummy, multicentre clinical trials. In the monotherapy study [5], 1,250 patients with inadequately controlled type 2 diabetes received either PIO $(n=624)$ or GLIC ( $n=626)$. In the combination therapy study [6], 630 patients whose type 2 diabetes was inadequately treated with MET received either PIO+MET $(n=317)$ or GLIC+ MET $(n=313)$. Both studies had a 16-week forced dosetitration phase and a 36-week maintenance phase. In both studies, patients were titrated to the maximum tolerated
Fig. 1 Disposition of patients screened. a Monotherapy study. b Combination therapy study

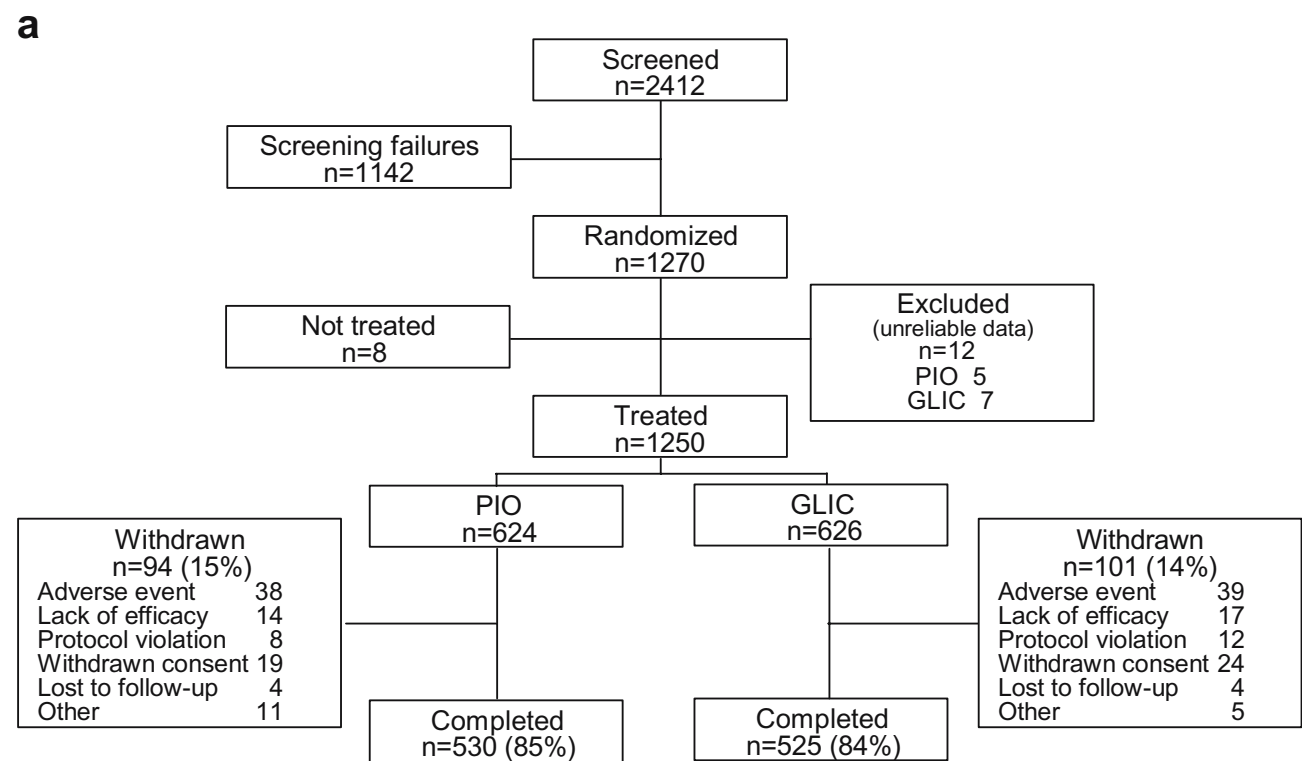

b

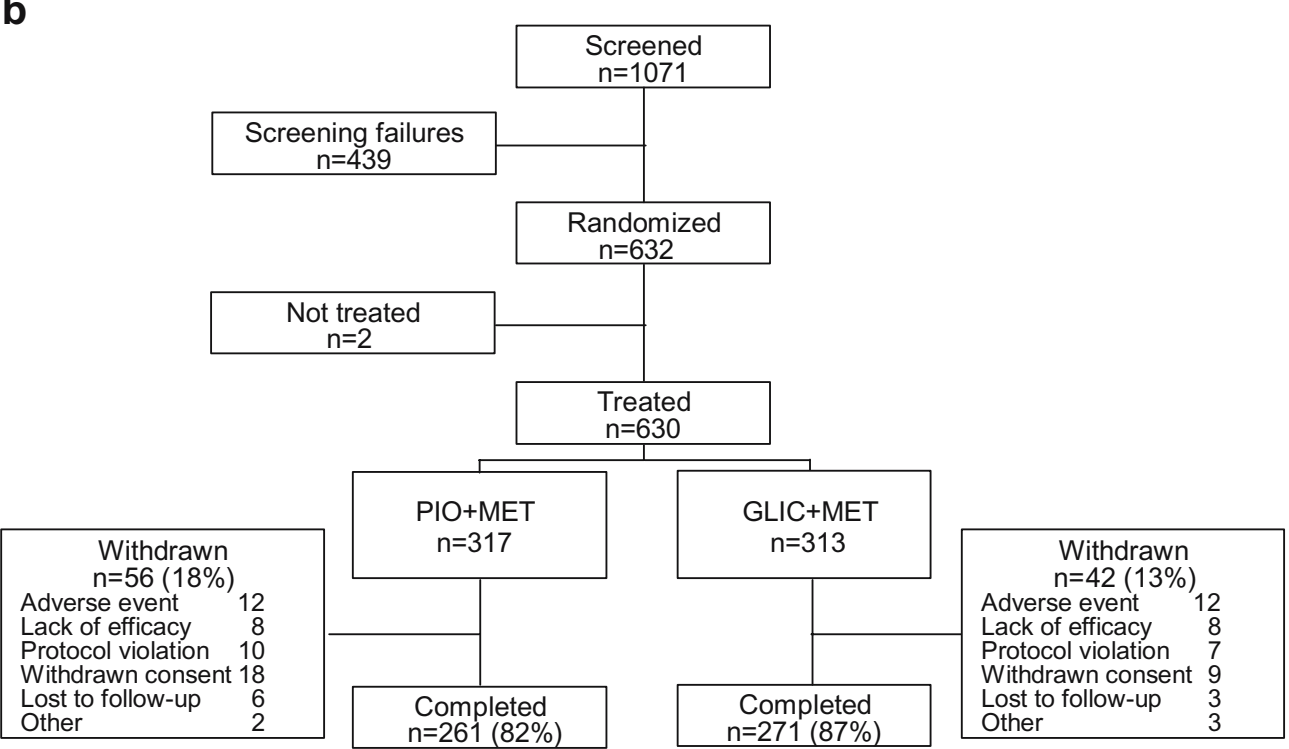


dose, not to exceed $45 \mathrm{mg}$ for PIO or $160 \mathrm{mg}$ twice daily for GLIC. In the combination study, MET was administered at the pre-study dose, which was $\geq 50 \%$ of the maximum recommended dose or the maximum tolerated dose (whichever was lower). The dose of MET remained unchanged throughout the study.

Men and women aged 35-75 years were eligible for the monotherapy study if they had type 2 diabetes that was inadequately treated by diet alone $\left(\mathrm{HbA}_{1} \mathrm{c} \geq 7.5\right.$ to $\left.\leq 11.0 \%\right)$, and were eligible for the MET combination study if they had type 2 diabetes that was inadequately managed $\left(\mathrm{HbA}_{1} \mathrm{c} \geq 7.5\right.$ to $\left.\leq 11.0 \%\right)$ with MET alone (at $\geq 50 \%$ of the maximum recommended dose or at the maximum tolerated dose for $\geq 3$ months). Additional inclusion criteria included stable or worsening glycaemic control over a period of at least 3 months. For the combination study, an additional inclusion criterion indicated that fasting serum C-peptide levels must be $\geq 0.50 \mathrm{nmol} / 1(\geq 1.5 \mathrm{ng} / \mathrm{ml})$. Patients who had previously received glucose-lowering drugs were excluded from the monotherapy study. Previous treatment with insulin, a sulphonylurea or a thiazolidinedione resulted in exclusion from the combination therapy study. Patient disposition for each trial is shown in Fig. 1. The most common reason for screening failure was that a patient's $\mathrm{HbA}_{1} \mathrm{c}$ value was outside the range specified in the inclusion criteria. A similar proportion of patients in each treatment group ( $>80 \%)$ completed the trial.

The ethics committee for each site approved each study protocol and all patients gave written informed consent prior to study entry. The study was conducted in accordance with the Declaration of Helsinki and Good Clinical Practice of the European Community.

Efficacy measurements The primary endpoint for each trial was $\mathrm{HbA}_{1} \mathrm{c}$. Secondary endpoints included fasting plasma glucose, fasting serum insulin and lipids. All data provided in the present analyses were derived from prospectively defined trial endpoints.

Blood samples for assessment of fasting serum insulin and fasting plasma glucose were collected at baseline and Weeks $4,8,12,16,24,32,42$ and 52 as previously de- scribed for these trials $[5,6]$. The values obtained were used for the calculation of homeostasis model assessment$\mathrm{S}$ (HOMA-\%S, which is a surrogate for insulin sensitivity) and HOMA-\%B (a surrogate for beta cell activity) $[12,13]$. Patients fasted the night prior to blood sampling and did not take their morning dose of study drug until after blood sampling. Values for HOMA- $\% \mathrm{~S}$ and $\mathrm{HOMA}-\% \mathrm{~B}$ were calculated using a computer program from the Diabetes Research Laboratories (Oxford, UK) [13]. Values for the quantitative insulin sensitivity check index (QUICKI, another surrogate for insulin sensitivity) were calculated as $1 /$ ( $\log _{10}$ fasting serum insulin $+\log _{10}$ fasting plasma glucose) [14]. Triglycerides, NEFAs and HDL cholesterol were assessed at baseline and Weeks 8, 16, 24, 32, 42 and 52 as previously described $[5,6]$. The atherogenic index of plasma (AIP) was calculated as $\log _{10}$ (triglycerides : HDL cholesterol) [15].

Statistical analysis The monotherapy and combination therapy studies were analysed separately. Repeated measures analysis of variance was used to compare the effects of PIO-based therapy with those of GLIC-based therapy. The repeated measures model employed an unstructured covariance matrix and included treatment, time, treatmenttime interaction and the baseline value of the dependent variable as independent variables. Treatment and time were fixed effects. Least-squares means from the model were used to estimate the treatment effects at each time point The least-squares means of the treatment groups were then compared at each time point using the Student's $t$-test. A $p$ value of less than 0.05 was considered statistically significant. Results are expressed as means \pm SD for baseline values and as means \pm SEM for least-squares means.

\section{Results}

Baseline patient characteristics were generally similar for the PIO and GLIC groups in each trial (as previously published $[5,6])$ and are provided in Table 1. Each patient population was representative of a type 2 diabetes cohort

Table 1 Baseline clinical characteristics

\begin{tabular}{|c|c|c|c|c|}
\hline & PIO $(n=624)$ & GLIC $(n=626)$ & PIO+MET $(n=317)$ & GLIC + MET $(n=313)$ \\
\hline Age (years) & $56 \pm 9.5$ & $56 \pm 9.6$ & $56 \pm 9.2$ & $57 \pm 9.0$ \\
\hline Gender ( $\%$ male $)$ & $61.4 \%$ & $61.7 \%$ & $50.8 \%$ & $49.2 \%$ \\
\hline Duration of diabetes at study start (years) & $2.8 \pm 3.8$ & $3.0 \pm 3.8$ & $5.8 \pm 5.1$ & $5.5 \pm 5.1$ \\
\hline Body weight $(\mathrm{kg})$ & $90.7 \pm 18.6$ & $88.1 \pm 16.9$ & $91.8 \pm 16.2$ & $92.7 \pm 17.4$ \\
\hline $\operatorname{BMI}\left(\mathrm{kg} / \mathrm{m}^{2}\right)$ & $31.7 \pm 6.0$ & $30.6 \pm 5.1$ & $32.6 \pm 5.0$ & $32.6 \pm 5.8$ \\
\hline $\mathrm{HbA}_{1} \mathrm{c}(\%)$ & $8.7 \pm 1.0$ & $8.7 \pm 1.1$ & $8.7 \pm 1.0$ & $8.5 \pm 0.9$ \\
\hline Fasting plasma glucose $(\mathrm{mmol} / \mathrm{l})$ & $11.1 \pm 2.8$ & $11.2 \pm 2.9$ & $11.8 \pm 3.1$ & $11.3 \pm 2.6$ \\
\hline Fasting plasma insulin (pmol/1) & $104.2 \pm 81.9$ & $103.5 \pm 114.0$ & $106.3 \pm 81.3$ & $104.2 \pm 69.9$ \\
\hline C-peptide (nmol/l) & $1.3 \pm 0.5$ & $1.3 \pm 0.5$ & $1.2 \pm 0.4$ & $1.2 \pm 0.4$ \\
\hline Triglycerides $(\mathrm{mmol} / \mathrm{l})$ & $2.6 \pm 2.1$ & $2.8 \pm 3.2$ & $2.9 \pm 1.9$ & $2.8 \pm 1.9$ \\
\hline NEFA (mmol/1) & $0.65 \pm 0.26$ & $0.64 \pm 0.33$ & $0.73 \pm 0.25^{\mathrm{a}}$ & $0.73 \pm 0.26^{\mathrm{a}}$ \\
\hline
\end{tabular}

The data shown are means \pm SD.

${ }^{a} n=89$ 
with obesity (as indicated by BMI) and hyperinsulinaemia (based on fasting serum insulin measurements). Patients in the combination study had a longer duration of diabetes. Patients randomised to PIO monotherapy had higher mean body weight and BMI than patients randomised to GLIC monotherapy $(p<0.05)$.

Insulin sensitivity assessments At endpoint, the PIO and $\mathrm{PIO}+\mathrm{MET}$ therapies had increased HOMA- $\% \mathrm{~S}$ relative to baseline values, whereas GLIC and GLIC+MET had decreased HOMA-\%S (Fig. 2a, b). In both studies, HOMA-\% $\mathrm{S}$ was significantly higher in the PIO group than in the corresponding GLIC group at endpoint $(p<0.001)$. In the $\mathrm{PIO}$ and $\mathrm{PIO}+\mathrm{MET}$ groups, HOMA- $\% \mathrm{~S}$ had increased to values greater than baseline by Week 4 and remained elevated throughout the duration of the study ( $p<0.001$ for all time points). In contrast, both GLIC and GLIC+MET resulted in decreases in $\mathrm{HOMA}-\% \mathrm{~S}$ relative to baseline at
Week 4 and thereafter $(p<0.001$ for all time points). In the $\mathrm{PIO}$ and PIO+MET groups, increases in QUICKI paralleled those of HOMA-\%S; GLIC and GLIC+MET produced smaller increases in QUICKI (Fig. 2c, d). Treatment differences between PIO and GLIC were significantly different for both assessments of insulin sensitivity $(p<0.001$ for monotherapy and combination therapy) at all postbaseline time points.

Assessment of beta cell activity PIO, GLIC, PIO+MET and GLIC+MET all produced significant increases in HOMA$\% \mathrm{~B}$ (surrogate for beta cell activity) relative to baseline values (Fig. 2e, f). GLIC-based regimens resulted in more rapid and greater increases in $\mathrm{HOMA}-\% \mathrm{~B}$, while patients receiving $\mathrm{PIO}$ or $\mathrm{PIO}+\mathrm{MET}$ experienced more gradual and smaller increases in HOMA-\%B. Although HOMA-\%B values decreased in the two GLIC groups following the titration period, they remained above baseline values and
Fig. 2 Time courses of HOMA$\% \mathrm{~S}(\mathbf{a}, \mathbf{b}), \mathrm{QUICKI}(\mathbf{c}, \mathbf{d})$, and HOMA-\%B (e, f). Data from the monotherapy study are shown in the column on the left, while data from the combination study are shown in the column on the right. The data points are means \pm SEM. ${ }^{*} p<0.001$ vs GLIC; ${ }^{\dagger} p<0.001$ vs GLIC+ MET. PIO, filled circles; GLIC, open circles; $\mathrm{PIO}+\mathrm{MET}$, filled inverted triangles; GLIC+MET, open inverted triangles
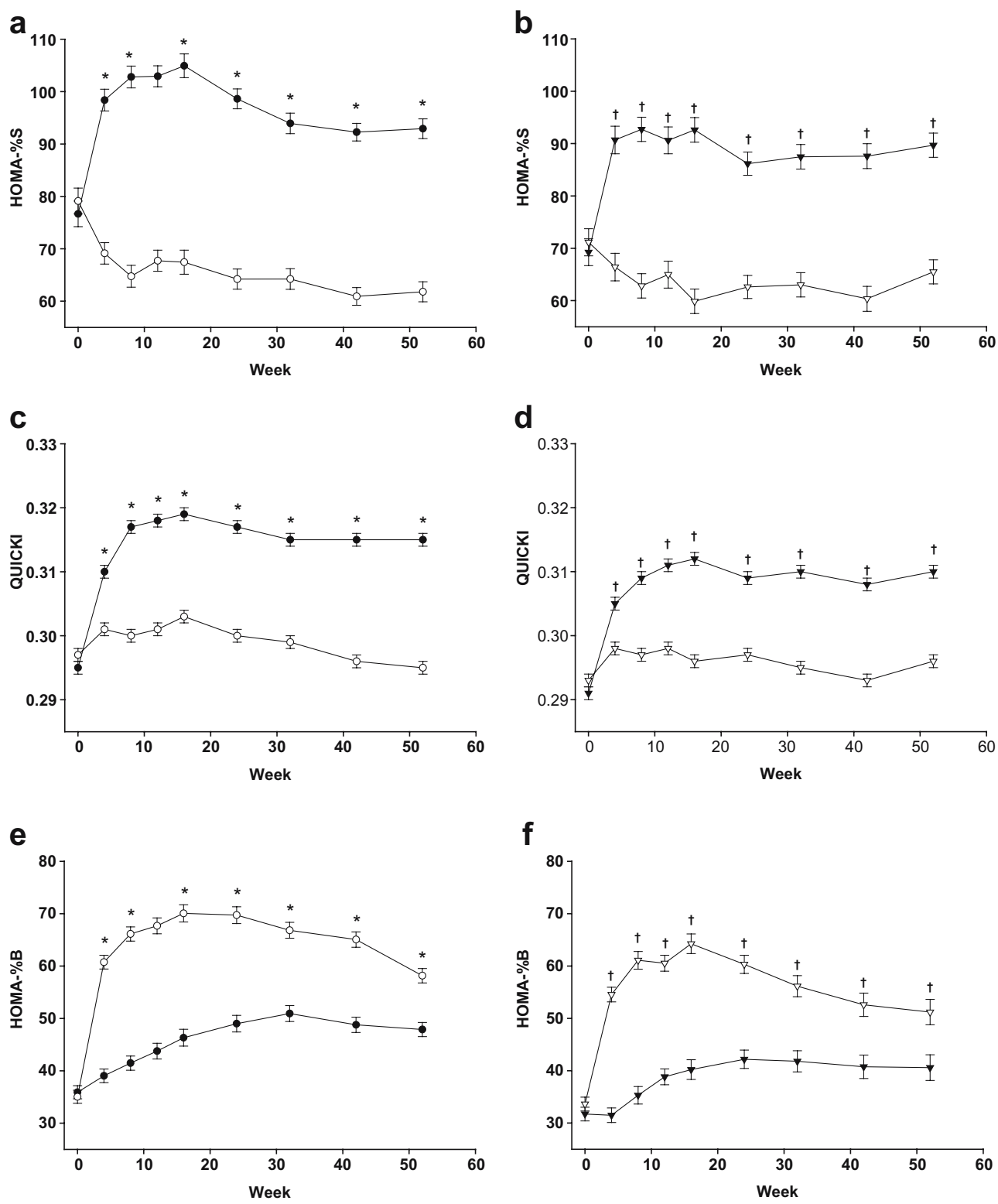
Fig. 3 Time courses of AIP $(\mathbf{a}, \mathbf{b})$ and triglycerides (c). Data from the monotherapy study are shown in the column on the left, while data from the combination study are shown in the column on the right. Time courses of changes in levels of triglycerides during the monotherapy study have been published previously [5]. The data points are means \pm SEM. ${ }^{*} p<0.001$ vs GLIC; ${ }^{\dagger} p<0.001$ vs GLIC+ MET; ${ }^{*} p<0.05$ vs GLIC+MET. PIO, filled circles; GLIC, open circles; PIO+MET, filled inverted triangles; GLIC+MET, open inverted triangles
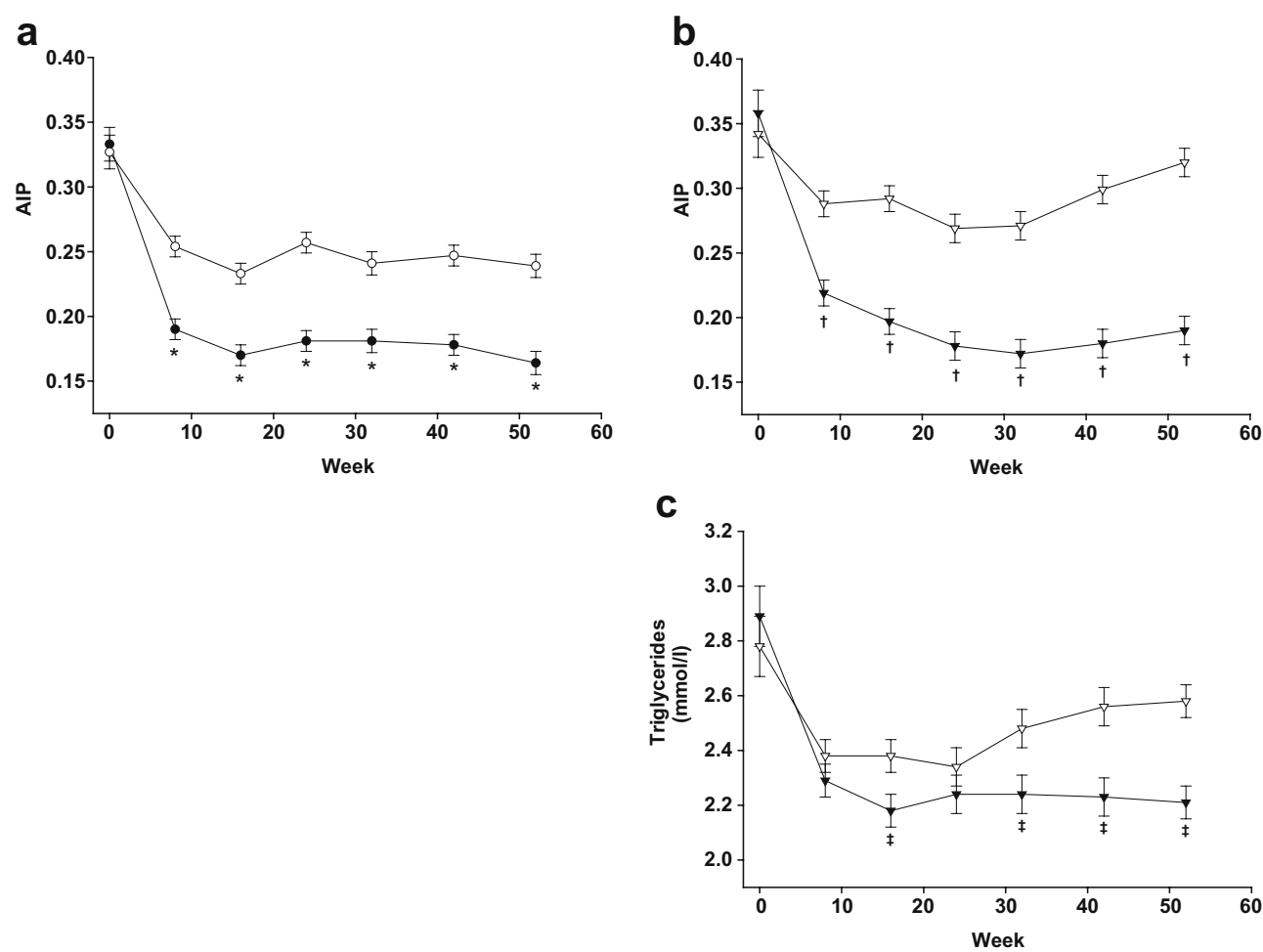

were significantly higher than those in the corresponding PIO group for the duration of the study.

Lipids All four treatment groups demonstrated significantly reduced AIP values relative to baseline from Week 4 through Week $52(p<0.001$ for all groups; Fig. 3a, b). The reductions observed in the PIO and PIO+MET groups were significantly greater than those in the corresponding GLIC group at all time points. Time courses for changes in triglycerides and NEFA during the monotherapy study have been reported previously [5]. In the combination study, triglyceride levels were acutely reduced compared with baseline by both therapies (Fig. 3c). Triglyceride levels were significantly lower in the PIO+MET group than in the GLIC+MET group at Week 16 and from Week 26 through Week 52, as triglyceride levels tended to increase toward baseline levels in the GLIC+MET group. Both PIO+MET and GLIC+MET produced significant reductions in NEFA levels from baseline to endpoint $(0.73 \mathrm{mmol} / \mathrm{l}$ to $0.61 \mathrm{mmol} /$ 1 for $\mathrm{PIO}+\mathrm{MET}, p<0.0001 ; 0.73 \mathrm{mmol} / 1$ to $0.68 \mathrm{mmol} / \mathrm{l}$ for GLIC+MET, $p=0.021$ ); these reductions were significantly greater in the PIO+MET group $(-16.4 \%)$ than in the GLIC+MET group $(-6.8 \%, p=0.044)$.

Safety The time course of body weight for each treatment group is shown in Fig. 4. Each regimen resulted in weight gains from baseline to endpoint. Patients receiving PIO were heavier at baseline than those receiving GLIC. By Week 4, body weights were no longer different between the two groups and remained similar until Week 32. At Weeks 42 and 52, patients on PIO had higher body weights than those on GLIC. Patients receiving PIO+MET also gained slightly more weight than those receiving GLIC+MET. Those in the GLIC+MET group were heavier than patients in the PIO+MET group at baseline through Week 16, but not at later time points in the study.
Fig. 4 Time courses of changes in body weight during the monotherapy study (a) and the combination study (b). The data points are means \pm SEM. PIO, filled circles; GLIC, open circles; $\mathrm{PIO}+\mathrm{MET}$, filled inverted triangles; GLIC+MET, open inverted triangles
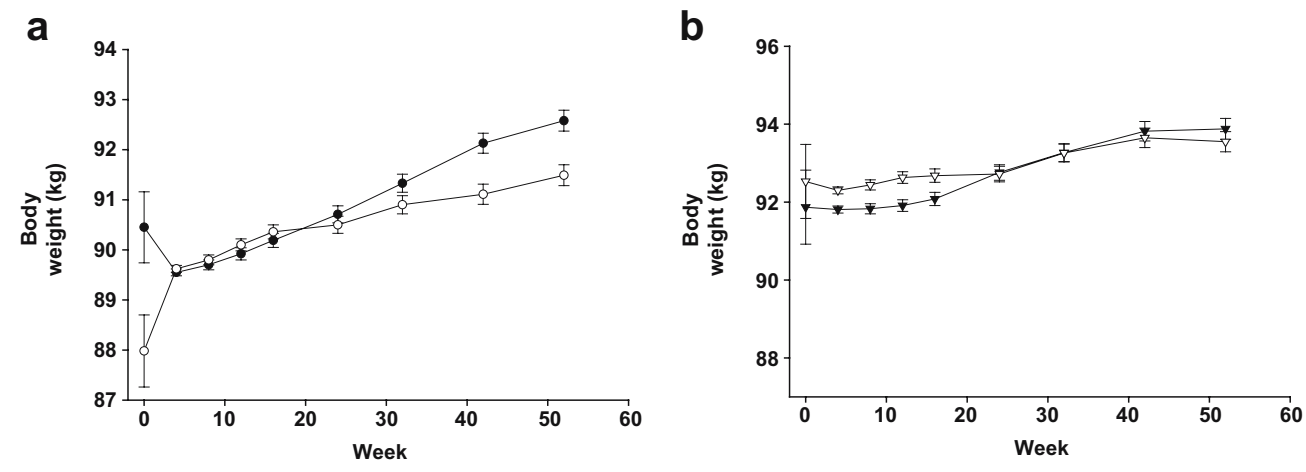


\section{Discussion}

PIO and GLIC have been shown to provide similar degrees of glycaemic control (i.e. reductions in $\mathrm{HbA}_{1} \mathrm{c}$ ) when compared as monotherapies and in combination with MET $[5,6]$. The present analysis extends previous observations by comparing the effects of these oral antihyperglycaemic medications on insulin sensitivity, insulin secretion activity of the beta cells, and lipid parameters that are associated with insulin sensitivity in adults with type 2 diabetes, with an emphasis on the relative time courses of these changes. We found that PIO-based regimens enhanced insulin sensitivity and produced a more favourable lipid profile compared with GLIC-based monotherapy or combination therapy.

In this analysis, HOMA- $\% \mathrm{~S}$ and QUICKI were employed as surrogates for insulin sensitivity. Due to the large numbers of patients studied in these trials, the use of more sophisticated and invasive measures (e.g. euglycaemichyperinsulinaemic clamps, frequently sampled IVGTTs) was not feasible. As measures of insulin sensitivity/resistance, HOMA-\%S and QUICKI have both shown strong correlations with euglycaemic-hyperinsulinaemic clamp studies [14, 16-18].

Compared with patients on GLIC, insulin sensitivity was significantly increased at the first point of measurement (Week 4) in patients receiving monotherapy or combination therapy with PIO and remained elevated throughout the duration of the 52-week study. In addition, PIO-based regimens significantly reduced fasting serum insulin levels, C-peptide levels, and 32-33 split pro-insulin levels over the 52-week time course, while GLIC-based regimens were associated with net increases in each of these measures [5]. These data are consistent with previous studies investigating the effects of PIO monotherapy on insulin sensitivity $[19,20]$, and highlight an important difference between the mechanisms of action of PIO (increasing insulin sensitivity) and GLIC (increasing insulin secretion). This distinction may be important in the long-term care of patients with type 2 diabetes given the association of insulin resistance with the development of cardiovascular complications in this population [8-11].

Patients receiving PIO-based regimens demonstrated more moderate increases in HOMA- $\% \mathrm{~B}$ than those receiving GLIC-based therapies; however, patients in the PIO groups did not exhibit a waning of effect after the titration phase of the study. The use of HOMA- $\% \mathrm{~B}$ in patients treated with secretagogues is acceptable, provided that the measure is interpreted as an assessment of beta cell activity as opposed to beta cell health or pathology [12]. The PIO-based therapies appeared to have beneficial effects on both of the core defects of type 2 diabetes, insulin resistance (as assessed by HOMA-\%S and QUICKI) and beta cell activity (as assessed by HOMA-\%B). Improving both of these components of insulin homeostasis in concert could be more beneficial than improving either component alone [21].

PIO has previously been found to elicit beneficial lipidrelated effects, reducing triglyceride and NEFA levels while raising HDL cholesterol levels $[5,6]$. In the present ana- lyses, PIO-based treatments were associated with early reductions in AIP and triglyceride levels; these parameters were decreased to a significantly greater extent in the PIO groups compared with the corresponding GLIC group. Of additional interest are the parallel time courses of improvements in HOMA-\%S and favourable alterations in lipids (reductions in AIP, triglycerides and NEFA) observed in the PIO monotherapy and combination therapy groups. These findings are consistent with the established relationship between triglycerides and insulin resistance [22-25]. Moreover, they are in agreement with previous reports that reductions in elevated circulating NEFA levels result in improved insulin sensitivity in patients with type 2 diabetes $[26,27]$ due to the capacity of NEFA to reduce glucose transport and phosphorylation in human skeletal muscle $[28,29]$. As AIP is inversely correlated with HOMA- $\% \mathrm{~S}$ [30], enhanced insulin sensitivity would be expected to be associated with a decreased AIP, as observed in the present analyses.

After 52 weeks of therapy, PIO and PIO+MET were associated with slight, but significant increases in LDL cholesterol levels and substantially greater increases in HDL cholesterol levels compared with GLIC and GLIC+MET, respectively $[5,6]$. Consequently, total cholesterol/HDL cholesterol ratios were significantly reduced in both PIO groups. The ratio of total cholesterol : HDL cholesterol was demonstrated to be a useful and simple index of the risk of ischaemic heart disease in men during the Quebec Cardiovascular Study [31]. Similarly, AIP is an independent predictor of angiographically documented coronary artery disease [32]. By inference, a reduction in AIP and/or the total cholesterol : HDL cholesterol ratio may lower overall cardiovascular risk. As AIP is inversely correlated with LDL particle size [15], the reductions in AIP suggest that PIO-based therapy may have caused a shift from small, dense LDL particles to larger, less atherogenic LDL particles, which would also explain the slight increases in LDL cholesterol levels. Consistent with this interpretation, PIO has previously been shown to increase LDL particle size [33].

During the study, mean body weight increased in all treatment groups. Our findings are consistent with previous reports on PIO and sulphonylurea usage $[34,35]$. In patients with type 2 diabetes treated with PIO, weight gain and enhancement of insulin sensitivity have been associated with increased subcutaneous fat and simultaneous reductions in visceral abdominal fat [36]. This redistribution of fat may explain the concomitant weight gain and increased insulin sensitivity observed in these patients [34]. Of interest, despite gaining weight when treated with pioglitazone, patients in the present studies exhibited improved glycaemic control, improved insulin sensitivity, decreased triglycerides and increased HDL cholesterol levels.

In the Quebec Cardiovascular Study, which investigated a general population, hyperinsulinaemia in combination with high triglycerides or low HDL cholesterol was associated with an increased risk of cardiovascular disease $[37,38]$. By inference, reductions in hyperinsulinaemia and hypertriglyceridaemia and/or increases in HDL cholesterol 
should decrease cardiovascular risk. In a Finnish study on people with type 2 diabetes, factor analysis demonstrated that the cluster of increased insulin, elevated triglycerides, reduced HDL cholesterol and high BMI increased the risk of CHD [39]. Insulin resistance, as estimated using HOMA, has also been shown to be an independent predictor of cardiovascular complications in patients with type 2 diabetes [40]. The studies described in this report have demonstrated that, over a 1-year period, the administration of PIO as monotherapy or in combination with MET provided more beneficial outcomes compared with GLIC-based therapies with respect to insulin sensitivity, triglycerides, AIP and NEFA in patients with type 2 diabetes. Given that PIO and GLIC exhibited similar antihyperglycaemic efficacy in terms of $\mathrm{HbA}_{1} \mathrm{c}$, these additional beneficial effects of PIO treatment cannot be explained by its glucose-lowering activity alone. The additional benefits associated with PIO-based regimens may potentially be of value in decreasing cardiovascular risk in patients with type 2 diabetes. A study is currently underway to determine whether PIO (versus placebo) reduces cardiovascular morbidity and mortality when used as an adjunct to current therapy in patients with type 2 diabetes [41].

Acknowledgements The authors thank M. A. Campbell and T. Cravens for assistance in the preparation of this manuscript. In addition to the authors, the following investigators participated in the monotherapy study: Australia: J. Best, R. Coles, W. Cheung, P. G. Colman, M. D'Emden, G. Fulcher, J. Graham, M. Guha, R. Moses, J. Prins, K. Stanton, T. Welborn. Belgium: A. Chachati, A. Debruyne, E. Demanet, E. Duvivier, H. Penninckx, K. Van Acker, F. Van Kerckhoven, A. Verhaegen, C. Wouters. Canada: M. Boctor, R. Brossiot, J. L. Chiasson, A. Edwards, C. Garceau, C. Godin, P. Hardin, H. Tildesley, P. Hierlihy, D. Knight, G. Levine, P. Maheux, T. Monchesky, C. Richard, R. Roux, E. Ur, V. Woo, J. F. Yale. Croatia: Z. Beer, Z. Crncevic-Orlic, V. Goldoni, S. Kokic, V. Profozic, V. Zjacic-Rotkvic. Denmark: P. Eskildsen, J. Faber, K. Hermansen, T. Krarup, S. Madsbad. Estonia: I. Alt, S. Korsten, A. Rosenthal, M. Vask, M. Viigimaa, M. Treial, M. Turkson. Finland: P. Ebeling, J. Eriksson, H. Haapamaki, P. Himanen, M. Honkasalo, J. Hopsu, S. Junnila, M. Jurvanen, L. Juurinen, T. Kaitila, E. Karonen, S. Keinanen-Kiukkaanniemi, P. Kivi, J. Koski, E. Kujansuu, L. Loman, T. Piippo, K. Piispanen, M. Pitkanen, M. Saarinen, P. Salmela, R. Siren, A. Strandberg, M. Vahatalo. Iceland: A. Hreidarsson. Israel: H. Bar-On, J. Cohen, I. Harman Boehm, A. Jaffe, E. Karnieli, H. Knobler, O. Minuchin, I. Raz, J. Wainstein, Y. Yerushalmi. Poland: E. Bandurska-Stankiewicz, W. Grzeszczak, D. Jaruga-Zytkiewicz, K. Jusiak, I. Kinalska, J. Lopatynski, M. Polaszewska-Muszynska, A. Stankiewicz, Z. Stepien, C. Strugala, H. Szczecinska. Portugal: J. M. Boavida. Romania: A. Albota, P. A. Babes, I. M. Bruckner, R. Gagiu, G. Ghise, M. Graur, C. Ionescu-Tirgoviste, M. Morosanu, M. Mota, P. V. Nafornita, A. Popescu, A. I. Rivis, M. Stamoran, G. Suciu, M. Toba. Slovak Republic: B. Krahulec, T. Kupcova, M. Macko, E. Nehajova, J. Okapcova, M. Porubska, P. Razus, I. Tkac, E. Toserova, V. Uliciansky, J. Vozar. Slovenia: M. Medvescek, M. Piletic. South Africa: A. Amod, L. Distiller, G. Ellis, H. Kaplan, W. Lourens, R. Moore, A. Motala, P. Naiker, H. Nortje, M. Omar, M. Seeber. Spain: S. Duran, E. Faure, J. L. Herrera Pombo, P. C. W. Hertogh, A. Jara, L. Montenegro. Switzerland: P. Gerber, A. Golay, T. Grueninger, S. Kradolfer. UK: P. Allamby, D. M. Allin, A. Baksi, R. W. Bilous, A. J. M. Boulton, S. Butt, J. S. Calvert, N. S. Campbell, G. Canning, M. Clamp, S. J. Cooper, A. J. J. Darrah, M. Davies, M. Duckworth, R. Edwards, C. Fox, J. A. Fulton, A. Gossage, I. Grandison, J. Ham, J. Hampton, D. K. Huggan, A. Jackson, G. R. Jones, N. Jones, W. A. K. Jones, D. Keating, D. Kerr, C. Langdon, C. Lennon, P. Maksimczyk, A. Matthews, C. H. McKee,
D. McKeith, C. McKinnon, J. E. Miller, P. Mooney, P. O’Hare, R. S. Paton, M. Pimm, J. Playfair, S. Rowlands, U. Savani, D. Semark, P. Shearer, M. E. Strelley, J. F. Tanqueray, J. S. Tilley, J. Vora, T. Wall, R. D. Weir, J. Wilding, P. Winacour, N. A. Wyatt, B. S. Young.

Additionally, the following investigators participated in the combination therapy study: Australia: J. Best, K. Bowen, S. Colagiuri, D. McIntyre, N. Petrovsky, T. Roberts, R. Simpson, S. Stranks. Bulgaria: A.-M. Borissova, L. Koeva, M. Pavlova, M. Petkova, M. Protich, T. Russev. Czech Republic: L. Dohnalova, J. Janousek, A. Klimovicova, M. Komrskova, J. Kotous, M. Kvapil, M. Melichar, J. Olsovsky, J. Perusicova, J. Povolny, E. Racicka, Z. Rusavy, F. Saudek, P. Skala, H. Vavrikova. France: Y. Lorcy. Germany: M. H. Bouzo, F. Bannout, H.-G. Dammann, U. Desaga, M. Dietrich, T. Drescher, T. Drobik, W. Grosskopf, H. Hager, A. Hamann, H. J. Hanefeld, M. Haslbeck, F. Ibbeken, R. Jerwan-Keim, U. Julius, H. Koch, K.-H. Krause, E. Luebbers-Klare, M. Mikolaiczik, U. A. Mueller, J. L. Partenheimer, J. Schoelmerich, G. Scholz, U. Schwedes, N. Singh-Anand, V. von Behren. Greece: M. E. Falagas, P. Kaldrimidis, A. Melidonis, G. P. Piaditis. Latvia: I. Andersone, B. Jegere, V. Stalte, A. Valtere, B. Vizina. Poland: E. BandurskaStankiewicz, D. Jaruga-Zytkiewicz, K. Jusiak, J. Lopatynski, A. Stankiewicz, C. Strugala. Romania: D. Cheta, N. Hancu, V. Serban. Turkey: T. Kabalak.

\section{Duality of interest}

B. Charbonnel and M. Roden have served as consultants for Takeda Europe R\&D Centre. S. Mariz and R. Urquhart are employees of Takeda Europe R\&D Centre. D. Johns, M. Mihm, M. Widel and M. Tan are employees and shareholders of Eli Lilly.

\section{References}

1. Campbell DB, Lavielle R, Nathan C (1991) The mode of action and clinical pharmacology of gliclazide: a review. Diabetes Res Clin Pract 14[Suppl 2]:S21-S36

2. Matthews DR, Cull CA, Stratton IM, Holman RR, Turner RC (1998) UKPDS 26: sulphonylurea failure in non-insulindependent diabetic patients over six years. UK Prospective Diabetes Study (UKPDS) Group. Diabet Med 15:297-303

3. Miyazaki Y, Mahankali A, Matsuda M et al (2001) Improved glycemic control and enhanced insulin sensitivity in type 2 diabetic subjects treated with pioglitazone. Diabetes Care 24: 710 719

4. Vosper H, Khoudoli GA, Graham TL, Palmer CN (2002) Peroxisome proliferator-activated receptor agonists, hyperlipidaemia, and atherosclerosis. Pharmacol Ther 95:47-62

5. Charbonnel BH, Matthews DR, Schernthaner G, Hanefeld M, Brunetti P (2004) A long-term comparison of pioglitazone and gliclazide in patients with type 2 diabetes mellitus: a randomized, double-blind, parallel-group comparison trial. Diabet Med (in press)

6. Matthews DR, Charbonnel B, Hanefeld M, Brunetti P, Schernthaner G (2004) Long-term therapy with addition of pioglitazone to metformin compared with the addition of gliclazide to metformin in patients with type 2 diabetes: a randomized, comparative study. Diabetes/Metab Res Rev (in press)

7. Expert Panel on Detection, Evaluation, And Treatment of High Blood Cholesterol In Adults (2001) Executive Summary of The Third Report of The National Cholesterol Education Program (NCEP) Expert Panel on Detection, Evaluation, And Treatment of High Blood Cholesterol In Adults (Adult Treatment Panel III). JAMA 285:2486-2497.

8. Howard G, O'Leary DH, Zaccaro D et al (1996) Insulin sensitivity and atherosclerosis. The Insulin Resistance Atherosclerosis Study (IRAS) Investigators. Circulation 93:1809-1817

9. Bao W, Srinivasan SR, Berenson GS (1996) Persistent elevation of plasma insulin levels is associated with increased cardiovascular risk in children and young adults. The Bogalusa Heart Study. Circulation 93:54-59 
10. Ruige JB, Assendelft WJ, Dekker JM, Kostense PJ, Heine RJ, Bouter LM (1998) Insulin and risk of cardiovascular disease: a meta-analysis. Circulation 97:996-1001

11. Turner RC, Millns H, Neil HA et al (1998) Risk factors for coronary artery disease in non-insulin dependent diabetes mellitus: United Kingdom Prospective Diabetes Study (UKPDS: 23). BMJ 316:823-828

12. Wallace TM, Levy JC, Matthews DR (2004) Use and abuse of HOMA modeling. Diabetes Care 27:1487-1495

13. Levy JC, Matthews DR, Hermans MP (1998) Correct homeostasis model assessment (HOMA) evaluation uses the computer program. Diabetes Care 21:2191-2192

14. Katz A, Nambi SS, Mather K et al (2000) Quantitative insulin sensitivity check index: a simple, accurate method for assessing insulin sensitivity in humans. J Clin Endocrinol Metab 85: 2402-2410

15. Dobiasova M, Frohlich J (2001) The plasma parameter log (TG/HDL-C) as an atherogenic index: correlation with lipoprotein particle size and esterification rate in apoB-lipoproteindepleted plasma (FER(HDL)). Clin Biochem 34:583-588

16. Bonora E, Targher G, Alberiche M et al (2000) Homeostasis model assessment closely mirrors the glucose clamp technique in the assessment of insulin sensitivity: studies in subjects with various degrees of glucose tolerance and insulin sensitivity. Diabetes Care 23:57-63

17. Yokoyama H, Emoto M, Fujiwara S et al (2004) Quantitative insulin sensitivity check index and the reciprocal index of homeostasis model assessment are useful indexes of insulin resistance in type 2 diabetic patients with wide range of fasting plasma glucose. J Clin Endocrinol Metab 89:1481-1484

18. Yokoyama H, Emoto M, Fujiwara S et al (2003) Quantitative insulin sensitivity check index and the reciprocal index of homeostasis model assessment in normal range weight and moderately obese type 2 diabetic patients. Diabetes Care 26:24262432

19. Herz M, Johns D, Reviriego J et al (2003) A randomized, double-blind, placebo-controlled, clinical trial of the effects of pioglitazone on glycemic control and dyslipidemia in oral antihyperglycemic medication-naive patients with type 2 diabetes mellitus. Clin Ther 25:1074-1095

20. Pavo I, Jermendy G, Varkonyi TT et al (2003) Effect of pioglitazone compared with metformin on glycemic control and indicators of insulin sensitivity in recently diagnosed patients with type 2 diabetes. J Clin Endocrinol Metab 88:1637-1645

21. Wallace TM, Levy JC, Matthews DR (2004) An increase in insulin sensitivity and basal beta-cell function in diabetic subjects treated with pioglitazone in a placebo-controlled randomized study. Diabet Med 21:568-576

22. Kelley DE, Goodpaster BH (2001) Skeletal muscle triglyceride. An aspect of regional adiposity and insulin resistance. Diabetes Care 24:933-941

23. Pan DA, Lillioja S, Kriketos AD et al (1997) Skeletal muscle triglyceride levels are inversely related to insulin action. Diabetes 46:983-988

24. Krssak M, Falk PK, Dresner A et al (1999) Intramyocellular lipid concentrations are correlated with insulin sensitivity in humans: a ${ }^{1} \mathrm{H}$ NMR spectroscopy study. Diabetologia 42:113116

25. Perseghin G, Scifo P, De Cobelli F et al (1999) Intramyocellular triglyceride content is a determinant of in vivo insulin resistance in humans: a ${ }^{1} \mathrm{H}-{ }^{13} \mathrm{C}$ nuclear magnetic resonance spectroscopy assessment in offspring of type 2 diabetic parents. Diabetes 48:1600-1606
26. Santomauro AT, Boden G, Silva ME et al (1999) Overnight lowering of free fatty acids with Acipimox improves insulin resistance and glucose tolerance in obese diabetic and nondiabetic subjects. Diabetes 48:1836-1841

27. Kelley DE, Williams KV, Price JC, McKolanis TM, Goodpaster BH, Thaete FL (2001) Plasma fatty acids, adiposity, and variance of skeletal muscle insulin resistance in type 2 diabetes mellitus. J Clin Endocrinol Metab 86:5412-5419

28. Roden M, Price TB, Perseghin G et al (1996) Mechanism of free fatty acid-induced insulin resistance in humans. J Clin Invest 97:2859-2865

29. Roden M, Krssak M, Stingl H et al (1999) Rapid impairment of skeletal muscle glucose transport/phosphorylation by free fatty acids in humans. Diabetes 48:358-364

30. Tan MH, Johns D, Glazer NB (2004) Pioglitazone reduces atherogenic index of plasma in patients with type 2 diabetes. Clin Chem 50:1184-1188

31. Lemieux I, Lamarche B, Couillard C et al (2001) Total cholesterol/HDL cholesterol ratio vs LDL cholesterol/HDL cholesterol ratio as indices of ischemic heart disease risk in men: the Quebec Cardiovascular Study. Arch Intern Med 161: 2685-2692

32. Frohlich J, Dobiasova M (2003) Fractional esterification rate of cholesterol and ratio of triglycerides to HDL-cholesterol are powerful predictors of positive findings on coronary angiography. Clin Chem 49:1873-1880

33. Winkler K, Konrad T, Fullert S et al (2003) Pioglitazone reduces atherogenic dense LDL particles in nondiabetic patients with arterial hypertension: a double-blind, placebo-controlled study. Diabetes Care 26:2588-2594

34. Miyazaki Y, Mahankali A, Matsuda M et al (2002) Effect of pioglitazone on abdominal fat distribution and insulin sensitivity in type 2 diabetic patients. J Clin Endocrinol Metab 87: 2784-2791

35. UK Prospective Diabetes Study (UKPDS) Group (1998) Intensive blood-glucose control with sulphonylureas or insulin compared with conventional treatment and risk of complications in patients with Type 2 diabetes (UKPDS 33). Lancet 352: 837-853

36. Evans DJ, Hoffmann RG, Kalkhoff RK, Kissebah AH (1984) Relationship of body fat topography to insulin sensitivity and metabolic profiles in premenopausal women. Metabolism 33: $68-75$

37. Lamarche B, Despres JP, Moorjani S, Cantin B, Dagenais GR, Lupien PJ (1996) Triglycerides and HDL-cholesterol as risk factors for ischemic heart disease. Results from the Quebec Cardiovascular Study. Atherosclerosis 119:235-245

38. Lamarche B, Despres JP, Moorjani S, Cantin B, Dagenais GR, Lupien PJ (1995) Prevalence of dyslipidemic phenotypes in ischemic heart disease (prospective results from the Quebec Cardiovascular Study). Am J Cardiol 75:1189-1195

39. Lehto S, Ronnemaa T, Pyorala K, Laakso M (2000) Cardiovascular risk factors clustering with endogenous hyperinsulinaemia predict death from coronary heart disease in patients with type 2 diabetes. Diabetologia 43:148-155

40. Bonora E, Formentini G, Calcaterra F et al (2002) HOMAestimated insulin resistance is an independent predictor of cardiovascular disease in type 2 diabetic subjects: prospective data from the Verona Diabetes Complications Study. Diabetes Care 25:1135-1141

41. Charbonnel B, Dormandy J, Erdmann E, Massi-Benedetti M, Skene A (2004) The prospective pioglitazone clinical trial in macrovascular events (PROactive): Can pioglitazone reduce cardiovascular events in diabetes? Study design and baseline characteristics of 5238 patients. Diabetes Care 27:1647-1653 